J. Nonlinear Var. Anal. 4 (2020), No. 3, pp. 357-376

Available online at http://jnva.biemdas.com

https://doi.org/10.23952/jnva.4.2020.3.03

\title{
A PARALLEL ITERATIVE METHOD FOR SOLVING A CLASS OF VARIATIONAL INEQUALITIES IN HILBERT SPACES
}

\author{
TRUONG MINH TUYEN ${ }^{1, *}$, TRAN XUAN QUY ${ }^{1}$, NGUYEN MINH TRANG $^{2}$ \\ ${ }^{1}$ Department of Mathematics and Informatics, Thai Nguyen University of Sciences, Thai Nguyen, Vietnam \\ ${ }^{2}$ Faculty of International training, Thainguyen University of Technology, Thai Nguyen, Vietnam
}

\begin{abstract}
The purpose of this paper is to introduce a new parallel iterative method for solving a variational inequality over the set of common fixed points of a finite family of sequences of nearly nonexpansive mappings. Solution theorems are established in a real Hilbert space.

Keywords. Variational inequality; Sequence of nearly nonexpansive mappings; Common fixed point; Common null point.
\end{abstract}

\section{INTRODUCTION}

Let $C$ be a nonempty convex and closed subset of a real Hilbert space $H$. The classical variational inequality problem initially studied by Stampacchia [17] for a nonlinear operator $F: C \rightarrow H$ is the problem of finding an element $x^{\dagger} \in D$ such that

$$
\left\langle F x^{\dagger}, x^{\dagger}-y\right\rangle \leq 0, \forall y \in D,
$$

where $D$ is a nonempty convex closed subset of $C$. We denote by $\mathrm{VI}_{D}(C, F)$ the problem (1.1). If $C \equiv H$, we denote this problem by $\operatorname{VI}(D, F)$. The problem $\operatorname{VI}(D, F)$ is equivalent to the problem of finding a fixed point of the mapping $P_{D}(I-\lambda F)$, for all $\lambda>0$, where $P_{D}$ is the metric projection from $H$ onto $D$. We know that if $F$ is Lipschitzian and strongly monotone, then, for small $\lambda>0$, the mapping $P_{D}(I-\lambda F)$ is a strict contraction. So, by the Banach contraction principle, the problem $\mathrm{VI}_{D}(C, F)$ has a unique solution $x^{\dagger}$ and the Picard iterative sequence $\left\{x_{n}\right\}$ defined by $x_{n+1}=P_{D}(I-\lambda F) x_{n}$ converge strongly to $x^{\dagger}$. The equivalence relation between the variational inequality problem and fixed point problem plays an important role in developing some efficient methods for solving variational inequality problems and related optimization problems; see. e,g., $[2,3,5,13]$ and the references therein. The problem of finding the fixed points of a nonexpansive mapping is the subject of the current interest related to variational inequality problems in functional analysis.

In 2000, Moudafi [10] proposed a viscosity approximation method for finding a fixed point of a nonexpansive mapping in Hilbert spaces, and then this method was considered by many authors. In 2001, Yamada [25] introduced a hybrid steepest-descent method for solving the

\footnotetext{
${ }^{*}$ Corresponding author.

E-mail addresses: tuyentm@tnus.edu.vn (T.M. Tuyen), quytx@tnus.edu.vn (T.X. Quy), nguyenminhtrang@ tnut.edu.vn (N.M. Trang).

Received January 16, 2020; Accepted April 27, 2020.
}

(C)2020 Journal of Nonlinear and Variational Analysis 
problem (1.1), where $F: H \rightarrow H$ is a Lipschitz strongly monotone operator and $D$ is the set of fixed points of a nonexpansive mapping $T: H \rightarrow H$, i.e., $D=F i x(T)$. Moreover, Yamada also considered the problem (1.1) in the case that $D$ is the set of common fixed points of a finite family of nonexpansive mappings $T_{1}, T_{2}, \ldots, T_{N}$, i.e., $D=\cap_{i=1}^{N} F i x\left(T_{i}\right)$. Moreover, the problem of finding a fixed point of a nonexpansive mapping $T$ when $T$ is given by the perturbation mappings $T_{n}, n \geq 1$, has been studied by many authors; see, e.g., Combettes [4], Kim and Xu [8]. We know that, in some special cases, the sequence of perturbation mappings $\left\{T_{n}\right\}$ is a sequence of nearly nonexpansive mappings (see [16, Example 5.1] or Example 5.1 of Section 5). The theory of variational inequalities over the set of common fixed points of a finite family of sequences of nearly nonexpansive mappings is now a considerable research interest in optimization theory.

In 2012, inspired by Aoyama et al. [1], Ceng, Ansari and Yao [2], Wong, Sahu and Yao [23], Sahu, Kang and Sagar [16] introduced a strong convergence theorem for finding a solution of the variational inequality over the set of common fixed points of a sequence of nearly nonexpansive mappings. Recently, the results presented in [16] were further extended by several authors; see, e.g., Tuyen and Ha [20] and Tuyen [21, 22]. In 2018, Tuyen [21] introduced a cyclic iterative method for a more general problem and proved the following result.

Theorem 1.1. Let $C$ be a nonempty closed convex subset of a real Hilbert space $H$. Let $F: C \rightarrow H$ be a k-Lipschitzian and $\eta$-strongly monotone operator and $V: C \rightarrow H$ be an L-Lipschitzian mapping. Let $\mathscr{T}_{i}=\left\{T_{i, n}\right\}, i=1,2, \ldots, N$ be sequences of nearly nonexpansive mappings from $C$ into itself with respect to the sequences $\left\{a_{i, n}\right\}$ such that $S=\cap_{i=1}^{N}$ Fix $\left(\mathscr{T}_{i}\right) \neq \emptyset$ and $T_{i}, i=$ $1,2, \ldots, N$, be mappings from $C$ into itself defined by $T_{i} x=\lim _{n \rightarrow \infty} T_{i, n} x$ for all $x \in C$. Suppose that $\cap_{i=1}^{N} F i x\left(T_{i}\right)=\cap_{i=1}^{N} F i x\left(\mathscr{T}_{i}\right), 0<\mu<2 \eta / k^{2}$ and $0 \leq \gamma L<\tau$, where $\tau=1-\sqrt{1-\mu\left(2 \eta-\mu k^{2}\right)}$. For an arbitrary $x_{0} \in C$, let $\left\{x_{n}\right\}$ be a sequence in $C$ generated by the following iterative method:

$$
\begin{aligned}
& y_{n}^{0}=x_{n}, \\
& y_{n}^{i}=\beta_{i, n} y_{n}^{i-1}+\left(1-\beta_{i, n}\right) T_{i, n} y_{n}^{i-1}, i=1,2, \ldots, N, \\
& x_{n+1}=P_{C}\left[\alpha_{n} \gamma V x_{n}+\left(I-\alpha_{n} \mu F\right) y_{n}^{N}\right], n \geq 0,
\end{aligned}
$$

where $\left\{\alpha_{n}\right\}$ is a sequence in $(0,1)$ and $\left\{\beta_{i, n}\right\}, i=1,2, \ldots, N$, are the sequences in $[a, b]$, with $a, b \in(0,1)$, which satisfy the following conditions:

i) $\lim _{n \rightarrow \infty} \alpha_{n}=0, \sum_{n=0}^{\infty} \alpha_{n}=\infty$;

ii) either $\sum_{n=0}^{\infty}\left|\alpha_{n+1}-\alpha_{n}\right|<\infty$ or $\lim _{n \rightarrow \infty} \alpha_{n+1} / \alpha_{n}=1$;

iii) $\sum_{n=0}^{\infty}\left|\beta_{i, n+1}-\beta_{i, n}\right|<\infty$ for all $i=1,2, \ldots, N$;

iv) either $\sum_{n=0}^{\infty} \mathscr{D}_{B}\left(T_{i, n}, T_{i, n+1}\right)<\infty$ or $\lim _{n \rightarrow \infty} \mathscr{D}_{B}\left(T_{i, n}, T_{i, n+1}\right) / \alpha_{n+1}=0$ for each $B \in \mathscr{B}(C)$, for all $i=1,2, \ldots, N$;

v) $\lim _{n \rightarrow \infty} a_{i, n} / \alpha_{n}=0$ for all $i=1,2, \ldots, N$.

Then, the sequence $\left\{x_{n}\right\}$ converges strongly to $x^{\dagger} \in S$, which is the unique solution of the variational inequality $\operatorname{VI}_{S}(C, \mu F-\gamma V)$.

\section{Remark 1.1.}

i) We denote by $\mathscr{B}(C)$ the collection of the bounded subsets of $C$ and

$$
\mathscr{D}_{B}\left(T_{n}, T_{n+1}\right)=\sup _{x \in B}\left\|T_{n+1} x-T_{n} x\right\|,
$$

for all $B \in \mathscr{B}(C)$. 
ii) Suppose $\sum_{n=0}^{\infty} \mathscr{D}_{B}\left(T_{n}, T_{n+1}\right)<\infty$ for each $B \in \mathscr{B}(C)$, where $\mathscr{T}=\left\{T_{n}\right\}$ is a sequence of nearly nonexpansive mappings from $C$ into itself with respect to the sequence $\left\{a_{n}\right\}$.

From the assumption $\sum_{n=0}^{\infty} \mathscr{D}_{B}\left(T_{n}, T_{n+1}\right)<\infty$, we have $\sum_{n=1}^{\infty}\left\|T_{n} x-T_{n+1} x\right\|<\infty$ for all $x \in B$. Hence $\left\{T_{n} x\right\}$ is a Cauchy sequence for each $x \in B$. So, $\left\{T_{n} x\right\}$ converges strongly to some point for each $x \in B$. For each $x \in C$, since the set $B=\{x\}$ belongs to $\mathscr{B}(C),\left\{T_{n} x\right\}$ converges to some point in $C$. Let $T: C \rightarrow C$ be a mapping defined by $T x=\lim _{n \rightarrow \infty} T_{n} x$ for each $x \in C$. It is easy to see that $T$ is a nonexpansive mapping. Now, for each $B \in \mathscr{B}(C), x \in B$ and $m, n \in \mathbb{N}$ with $m>n$, we have

$$
\begin{aligned}
\left\|T_{n} x-T_{m} x\right\| & \leq \sum_{k=n}^{m-1}\left\|T_{k} x-T_{k+1} x\right\| \\
& \leq \sum_{k=n}^{m-1} \mathscr{D}_{B}\left(T_{k}, T_{k+1}\right) \\
& \leq \sum_{k=n}^{\infty} \mathscr{D}_{B}\left(T_{k}, T_{k+1}\right) .
\end{aligned}
$$

Thus,

$$
\left\|T_{n} x-T x\right\|=\lim _{m \rightarrow \infty}\left\|T_{n} x-T_{m} x\right\| \leq \sum_{k=n}^{\infty} \mathscr{D}_{B}\left(T_{k}, T_{k+1}\right),
$$

for all $x \in B$. This implies that

$$
\mathscr{D}_{B}\left(T_{n}, T\right) \leq \sum_{k=n}^{\infty} \mathscr{D}_{B}\left(T_{k}, T_{k+1}\right) .
$$

Therefore, $\lim _{n \rightarrow \infty} \mathscr{D}_{B}\left(T_{n}, T\right)=0$.

iii) Suppose $\lim _{n \rightarrow \infty} \mathscr{D}_{B}\left(T_{n}, T\right)=0$ for each $B \in \mathscr{B}(C)$, where $T$ is a mapping from $C$ into itself. Then, $T$ is a nonexpansive mapping and $\operatorname{Fix}(\mathscr{T}) \subset \operatorname{Fix}(T)$.

In this paper, we give a parallel iterative method for finding a solution of the variational inequality $\mathrm{VI}_{S}(C, \mu F-\gamma V)$, where $S$ is the set of the common fixed points of a finite family of sequences of nearly nonexpansive mappings. We prove the strong convergence theorem under the following conditions (see, Theorem 3.1):

i) $\lim _{n \rightarrow \infty} \alpha_{n}=0, \sum_{n=0}^{\infty} \alpha_{n}=\infty$;

ii) $\mathscr{D}_{B}\left(T_{i, n}, T_{i}\right) \rightarrow 0$ for each $B \in \mathscr{B}(C)$, for all $i=1,2, \ldots, N$;

iii) $\lim _{n \rightarrow \infty} a_{i, n} / \alpha_{n}=0$ for all $i=1,2, \ldots, N$.

Next, in Section 4, we give some applications of the main theorem to the problem of finding a common fixed point of nonexpansive mappings or nonexpansive semigroups and the problem of finding a common null point of monotone operators in a real Hilbert space. Finally, in Section 5, we give a numerical example to illustrate the obtained results and show its performance.

\section{PRELIMINARIES}

Let $H$ be a real Hilbert space with inner product $\langle.,$.$\rangle and norm \|$.$\| . Let C$ be a nonempty convex closed subset of $H$. We know that, for each $x \in H$, there is a unique $P_{C} x \in C$ such that

$$
\left\|x-P_{C} x\right\|=\inf _{u \in C}\|x-u\|,
$$

and the mapping $P_{C}: H \rightarrow C$ defined by (2.1) is called the metric projection from $H$ onto $C$. 
Recall that a mapping $T: C \rightarrow H$ is said to be:

a) monotone if $\langle T x-T y, x-y\rangle \geq 0, \forall x, y \in C$;

b) $\eta$-strongly monotone if there exists a positive real number $\eta$ such that

$$
\langle T x-T y, x-y\rangle \geq \eta\|x-y\|^{2}, \forall x, y \in C ;
$$

c) $k$-Lipschitzian if there exists a constant $k>0$ such that

$$
\|T x-T y\| \leq k\|x-y\|, \forall x, y \in C .
$$

If $k=1$, then $T$ is called a nonexpansive mapping, and if $k \in[0,1)$, then $T$ is called a strict contraction.

Let $\mathscr{T}=\left\{T_{n}\right\}$ be a sequence of mappings from $C$ into itself. We denote by $\operatorname{Fix}(\mathscr{T})$ the set of common fixed points of the sequence $\mathscr{T}$, that is, $\operatorname{Fix}(\mathscr{T})=\cap_{n=1}^{\infty} \operatorname{Fix}\left(T_{n}\right)$. Fix a sequence $\left\{a_{n}\right\} \subset[0,1)$ such that $\lim _{n \rightarrow \infty} a_{n}=0$, and let $\left\{T_{n}\right\}$ be a sequence of mappings from $C$ into $H$. Then, $\left\{T_{n}\right\}$ is called a sequence of nearly nonexpansive mappings [23] with respect to the sequence $\left\{a_{n}\right\}$ if $\left\|T_{n} x-T_{n} y\right\| \leq\|x-y\|+a_{n}$, for all $x, y \in C$ and for all $n \in \mathbb{N}$.

We know that if $C$ is a bounded set and $T: C \rightarrow C$ is an asymptotically nonexpansive mapping, that is, there is a sequence $\left\{k_{n}\right\}$ such that, $k_{n} \geq 1$ for all $n, \lim _{n \rightarrow \infty} k_{n}=1,\left\|T^{n} x-T^{n} y\right\| \leq$ $k_{n}\|x-y\|$ for all $x, y \in C$, then $\mathscr{T}=\left\{T^{n}\right\}$ is a sequence of nearly nonexpansive mappings. Indeed, for all $x, y \in C$, we have

$$
\begin{aligned}
\left\|T^{n} x-T^{n} y\right\| & \leq k_{n}\|x-y\| \\
& =\|x-y\|+\left(k_{n}-1\right)\|x-y\| \\
& \leq\|x-y\|+\left(k_{n}-1\right) \operatorname{diam}(C) .
\end{aligned}
$$

Hence, $\mathscr{T}$ is a sequence of nearly nonexpansive mappings with respect to sequence $\left\{\left(k_{n}-\right.\right.$ 1) $\operatorname{diam}(C)\}$.

For an operator $A: H \rightarrow 2^{H}$, we define its domain, range and graph as follows:

$$
\begin{aligned}
& D(A)=\{x \in H: A x \neq \emptyset\}, \\
& R(A)=\cup\{A z: z \in D(A)\},
\end{aligned}
$$

and

$$
G(A)=\{(x, y) \in H \times H: x \in D(A), y \in A x\},
$$

respectively. The inverse $A^{-1}$ of $A$ is defined by

$$
x \in A^{-1} y \text { if and only if } y \in A x .
$$

The operator $A$ is said to be monotone if, for each $x, y \in D(A),\langle u-v, x-y\rangle \geq 0$ for all $u \in A x$ and $v \in A y$. We denote by $I$ the identity operator on $H$. A monotone operator $A$ is said to be maximal monotone if there is no proper monotone extension of $A$ or $R(I+\lambda A)=H$ for all $\lambda>0$ (see [15]). If $A$ is monotone, then we can define, for each $\lambda>0$, a nonexpansive single-valued mapping $J_{\lambda}^{A}: R(I+\lambda A) \rightarrow D(A)$ by $J_{\lambda}^{A}=(I+\lambda A)^{-1}$, which is called the resolvent of $A$. A monotone operator $A$ is said to satisfy the range condition if $\overline{D(A)} \subset R(I+\lambda A)$ for all $\lambda>0$, where $\overline{D(A)}$ denotes the closure of the domain of $A$.

Remark 2.1. If $A$ is a maximal monotone, then it satisfies the range condition.

The following lemmas will be needed in the sequel for the proof of main results in this paper. 
Lemma 2.1. Let $H$ be a real Hilbert space. For all $x, y \in H$ and $t \in[0,1]$, we have

a) $\|x+y\|^{2} \leq\|x\|^{2}+2\langle y, x+y\rangle$;

b) $\|(1-t) x+t y\|^{2}=(1-t)\|x\|^{2}+t\|y\|^{2}-t(1-t)\|x-y\|^{2}$.

Lemma 2.2. $[6,7]$ The metric projection mapping $P_{C}$ is characterized by the following properties:

a) $P_{C} x \in C$ for all $x \in H$;

b) $\left\langle x-P_{C} x, P_{C} x-y\right\rangle \geq 0$ for all $x \in H$ and $y \in C$;

c) $\|x-y\|^{2} \geq\left\|x-P_{C} x\right\|^{2}+\left\|y-P_{C} x\right\|^{2}$ for all $x \in H$ and $y \in C$;

d) $\left\langle P_{C} x-P_{C} y, x-y\right\rangle \geq\left\|P_{C} x-P_{C} y\right\|^{2}$ for all $x, y \in H$.

Lemma 2.3. [2] Let $V: C \rightarrow H$ be an L-Lipschitzian mapping and $F: C \rightarrow H$ be a $k$-Lipschitzian and $\eta$-strongly monotone operator. Then, for $0 \leq \gamma L<\mu \eta$,

$$
\langle x-y,(\mu F-\gamma V) x-(\mu F-\gamma V) y\rangle \geq(\mu \eta-\gamma L)\|x-y\|^{2}, \forall x, y \in C,
$$

that is, $\mu F-\gamma V$ is strongly monotone with coefficient $\mu \eta-\gamma L$.

Lemma 2.4. [25] Let $C$ be a nonempty subset of a real Hilbert space $H$. Suppose that $\lambda \in(0,1)$ and $\mu>0$. Let $F: C \rightarrow H$ be a k-Lipschitzian and $\eta$-strongly monotone operator on $C$. Define the mapping $G: C \rightarrow H$ by $G x=(I-\lambda \mu F) x, \forall x \in C$. Then $G$ is a strict contraction provided $\mu<2 \eta / k^{2}$. More precisely, for $\mu \in\left(0,2 \eta / k^{2}\right)$,

$$
\|G x-G y\| \leq(1-\lambda \tau)\|x-y\|, \forall x, y \in C,
$$

where $\tau=1-\sqrt{1-\mu\left(2 \eta-\mu k^{2}\right)}$.

Lemma 2.5. [6] Let $T$ be a nonexpansive self-map defined on a closed convex subset $C$ of a Hilbert space $H$. If $T$ has a fixed point, then I-T is demiclosed; that is, whenever $\left\{x_{n}\right\}$ is a sequence in $C$ weakly converging to some $x \in C$ and the sequence $\left\{(I-T) x_{n}\right\}$ strongly converges to some $y$, it follows that $(I-T) x=y$.

Lemma 2.6. [18] Let $A: D(A) \rightarrow 2^{H}$ be a monotone operator. For each $\lambda, \mu>0$ and $x \in$ $R(I+\lambda A) \cap R(I+\mu A)$, it holds

$$
\left\|J_{\lambda}^{A} x-J_{\mu}^{A} x\right\| \leq \frac{|\lambda-\mu|}{\lambda}\left\|x-J_{\lambda}^{A} x\right\| .
$$

Lemma 2.7. [9] Let $\left\{s_{n}\right\}$ be a real sequence that does not decrease at infinity, in the sense that there exists a subsequence $\left\{s_{n_{k}}\right\}$ so that $s_{n_{k}} \leq s_{n_{k}+1}, \forall k \geq 0$. For every $n>n_{0}$ define an integer sequence $\{\tau(n)\}$ as

$$
\tau(n)=\max \left\{n_{0} \leq k \leq n: s_{k}<s_{k+1}\right\} .
$$

Then $\tau(n) \rightarrow \infty$ as $n \rightarrow \infty$ for all $n>n_{0}, \max \left\{s_{\tau(n)}, s_{n}\right\} \leq s_{\tau(n)+1}$.

Lemma 2.8. [24] Let $\left\{a_{n}\right\}$ be a sequence of nonnegative numbers satisfying the condition

$$
a_{n+1} \leq\left(1-b_{n}\right) a_{n}+b_{n} c_{n}+\sigma_{n},
$$

where $\left\{b_{n}\right\},\left\{c_{n}\right\}$, and $\left\{\sigma_{n}\right\}$ are the sequences of real numbers such that

i) $\left\{b_{n}\right\} \subset[0,1], \sum_{n=0}^{\infty} b_{n}=+\infty$,

ii) $\limsup _{n \rightarrow \infty} c_{n} \leq 0$,

iii) $\sum_{n=0}^{\infty} \sigma_{n}<\infty$ or $\limsup _{n \rightarrow \infty} \sigma_{n} / b_{n} \leq 0$.

Then $\lim _{n \rightarrow \infty} a_{n}=0$. 


\section{MAin RESUlTS}

Let $C$ be a nonempty convex closed subset of a real Hilbert space $H$. Let $F: C \rightarrow H$ be a $k$-Lipschitzian and $\eta$-strongly monotone operator and $V: C \rightarrow H$ be an $L$-Lipschitzian mapping. Let $\mathscr{T}_{i}=\left\{T_{i, n}\right\}, i=1,2, \ldots, N$ be sequences of nearly nonexpansive mappings from $C$ into itself with respect to the sequences $\left\{a_{i, n}\right\}$ such that $S=\cap_{i=1}^{N} F i x\left(\mathscr{T}_{i}\right) \neq \emptyset$ and let $T_{i}, i=1,2, \ldots, N$, be mappings from $C$ into itself such that $\lim _{n \rightarrow \infty} \mathscr{D}_{B}\left(T_{i, n}, T_{i}\right)=0$. Suppose that $\cap_{i=1}^{N} F i x\left(T_{i}\right)=$ $\cap_{i=1}^{N} F i x\left(\mathscr{T}_{i}\right)$ and $0 \leq \gamma L<\tau$, where $\tau=1-\sqrt{1-\mu\left(2 \eta-\mu k^{2}\right)}$. We consider the following problem:

$$
\text { Find an element } x^{\dagger} \in S \text {, }
$$

such that $x^{\dagger}$ is a unique solution of the variational inequality $\mathrm{VI}_{S}(C, \mu F-\gamma V)$.

In order to solve Problem (3.1), we introduce the following parallel iterative method.

Algorithm 3.1. For an arbitrary $x_{0} \in C$, let $\left\{x_{n}\right\}$ be a sequence in $C$ generated by the following iterative method:

$$
\begin{aligned}
& y_{n}^{i}=\beta_{i, n} x_{n}+\left(1-\beta_{i, n}\right) T_{i, n} x_{n}, i=1,2, \ldots, N, \\
& \text { Chosse } i_{n} \text { such that }\left\|y_{n}^{i_{n}}-x_{n}\right\|=\max _{i=1,2, \ldots, N}\left\|y_{n}^{i}-x_{n}\right\|, \text { let } y_{n}=y_{n}^{i_{n}}, \\
& x_{n+1}=P_{C}\left[\alpha_{n} \gamma V x_{n}+\left(I-\alpha_{n} \mu F\right) y_{n}\right], n \geq 0,
\end{aligned}
$$

where $\left\{\alpha_{n}\right\}$ is a sequence in $(0,1)$ and $\left\{\beta_{i, n}\right\}, i=1,2, \ldots, N$, are the sequences in $[a, b]$, with $a, b \in(0,1)$.

We begin with the following proposition.

Proposition 3.1. In Algorithm 3.1, the sequence $\left\{x_{n}\right\}$ is bounded.

Proof. Taking $p \in S$ for each $i \in\{1,2, \ldots, N\}$, we have

$$
\begin{aligned}
\left\|y_{n}^{i}-p\right\| & \leq \beta_{i, n}\left\|x_{n}-p\right\|+\left(1-\beta_{i, n}\right)\left\|T_{i, n} x_{n}-T_{i, n} p\right\| \\
& \leq \beta_{i, n}\left\|x_{n}-p\right\|+\left(1-\beta_{i, n}\right)\left\|x_{n}-p\right\|+a_{i, n} \\
& =\left\|x_{n}-p\right\|+a_{i, n} .
\end{aligned}
$$

Next, from (3.3), we have

$$
\begin{aligned}
\left\|x_{n+1}-p\right\| & \leq \alpha_{n} \gamma L\left\|x_{n}-p\right\|+\alpha_{n}\|(\gamma V-\mu F) p\|+\left(1-\alpha_{n} \tau\right)\left\|y_{n}-p\right\| \\
& \leq \alpha_{n} \gamma L\left\|x_{n}-p\right\|+\alpha_{n}\|(\gamma V-\mu F) p\|+\left(1-\alpha_{n} \tau\right)\left(\left\|x_{n}-p\right\|+a_{i_{n}, n}\right) \\
& \leq\left[1-\alpha_{n}(\tau-\gamma L)\right]\left\|x_{n}-p\right\|+\alpha_{n}\|(\gamma V-\mu F) p\|+a_{i_{n}, n} .
\end{aligned}
$$

Since $\lim _{n \rightarrow \infty} a_{i, n} / \alpha_{n}=0$ for all $i=1,2, \ldots, N$, we find that there exists $K_{1}>0$ such that

$$
\frac{\alpha_{n}\|(\gamma V-\mu F) p\|+a_{i, n}}{\alpha_{n}} \leq K_{1}, \forall n \geq 0
$$


for all $i=1,2, \ldots, N$. Thus, from (3.4), we get that

$$
\begin{aligned}
\left\|x_{n+1}-p\right\| \leq & {\left[1-\alpha_{n}(\tau-\gamma L)\right]\left\|x_{n}-p\right\|+\alpha_{n} K_{1} } \\
\leq & \max \left\{\frac{K_{1}}{\tau-\gamma L},\left\|x_{n}-p\right\|\right\} \\
& \vdots \\
\leq & \max \left\{\frac{K_{1}}{\tau-\gamma L},\left\|x_{0}-p\right\|\right\},
\end{aligned}
$$

which implies that $\left\{x_{n}\right\}$ is bounded, so are $\left\{T_{i, n} x_{n}\right\},\left\{F y_{n}^{i}\right\}, i=1,2, \ldots, N$, and $\left\{V x_{n}\right\}$. This completes the proof.

Proposition 3.2. In Algorithm 3.1, if

$$
s_{n}=\left\|x_{n}-x^{*}\right\|^{2}, b_{n}=\frac{2 \alpha_{n}(\tau-\gamma L)}{1+\alpha_{n}(\tau-\gamma L)},
$$

and

$$
\begin{gathered}
c_{n}=\frac{1}{2(\tau-\gamma L)}\left\langle(\gamma V-\mu F) x^{*}, x_{n+1}-x^{*}\right\rangle, \\
\sigma_{n}=\frac{a(1-b)\left(1-\alpha_{n} \tau\right)}{1+\alpha_{n}(\tau-\gamma L)}\left\|T_{i_{n}, n} x_{n}-x_{n}\right\|^{2}, \sigma_{n}^{\prime}=\frac{K_{2}}{1+\alpha_{n}(\tau-\gamma L)} a_{i_{n}, n},
\end{gathered}
$$

for each $x^{*} \in S$, then

$$
s_{n+1} \leq\left(1-b_{n}\right) s_{n}+b_{n} c_{n}-\sigma_{n}+\sigma_{n}^{\prime} .
$$

Proof. Let $x^{*} \in S$ and $z_{n}=\alpha_{n} \gamma V x_{n}+\left(I-\alpha_{n} \mu F\right) y_{n}$. Since $x_{n+1}=P_{C}\left(z_{n}\right)$, we have

$$
\begin{aligned}
\| & x_{n+1}-x^{*} \|^{2} \\
= & \left\langle z_{n}-x^{*}, x_{n+1}-x^{*}\right\rangle+\left\langle P_{C} z_{n}-z_{n}, P_{C} z_{n}-x^{*}\right\rangle \\
\leq & \left\langle z_{n}-x^{*}, x_{n+1}-x^{*}\right\rangle \\
= & \left\langle\alpha_{n}\left(\gamma V x_{n}-\mu F x^{*}\right)+\left[\left(I-\alpha_{n} \mu F\right) y_{n}-\left(I-\alpha_{n} \mu F\right) x^{*}\right], x_{n+1}-x^{*}\right\rangle \\
= & \alpha_{n} \gamma\left\langle V x_{n}-V x^{*}, x_{n+1}-x^{*}\right\rangle+\alpha_{n}\left\langle(\gamma V-\mu F) x^{*}, x_{n+1}-x^{*}\right\rangle \\
& +\left\langle\left(I-\alpha_{n} \mu F\right) y_{n}-\left(I-\alpha_{n} \mu F\right) x^{*}, x_{n+1}-x^{*}\right\rangle \\
\leq & \alpha_{n} \gamma L\left\|x_{n}-x^{*}\right\| \cdot\left\|x_{n+1}-x^{*}\right\|+\alpha_{n}\left\langle(\gamma V-\mu F) x^{*}, x_{n+1}-x^{*}\right\rangle \\
& +\left(1-\alpha_{n} \tau\right)\left\|y_{n}-x^{*}\right\| .\left\|x_{n+1}-x^{*}\right\| \\
\leq & \frac{\alpha_{n} \gamma L}{2}\left(\left\|x_{n}-x^{*}\right\|^{2}+\left\|x_{n+1}-x^{*}\right\|^{2}\right)+\frac{\left(1-\alpha_{n} \tau\right)}{2}\left(\left\|y_{n}-x^{*}\right\|^{2}+\left\|x_{n+1}-x^{*}\right\|^{2}\right) \\
& +\alpha_{n}\left\langle(\gamma V-\mu F) x^{*}, x_{n+1}-x^{*}\right\rangle,
\end{aligned}
$$

which implies that

$$
\begin{aligned}
{\left[1+\alpha_{n}(\tau-\gamma L)\right]\left\|x_{n+1}-x^{*}\right\|^{2} \leq } & \alpha_{n} \gamma L\left\|x_{n}-x^{*}\right\|^{2}+\left(1-\alpha_{n} \tau\right)\left\|y_{n}-x^{*}\right\|^{2} \\
& +2 \alpha_{n}\left\langle(\gamma V-\mu F) x^{*}, x_{n+1}-x^{*}\right\rangle .
\end{aligned}
$$


Now, it follows from Lemma 2.1 that

$$
\begin{aligned}
\left\|y_{n}-x^{*}\right\|^{2} & =\left\|\beta_{i_{n}, n}\left(x_{n}-x^{*}\right)+\left(1-\beta_{i_{n}, n}\right)\left(T_{i_{n}, n} x_{n}-x^{*}\right)\right\|^{2} \\
& =\beta_{i_{n}, n}\left\|x_{n}-x^{*}\right\|^{2}+\left(1-\beta_{i_{n}, n}\right)\left\|T_{i_{n}, n} x_{n}-x^{*}\right\|^{2}-\beta_{i_{n}, n}\left(1-\beta_{i_{n}, n}\right)\left\|T_{i_{n}, n} x_{n}-x_{n}\right\|^{2} \\
& \leq \beta_{i_{n}, n}\left\|x_{n}-x^{*}\right\|^{2}+\left(1-\beta_{i_{n}, n}\right)\left(\left\|x_{n}-x^{*}\right\|+a_{i_{n}, n}\right)^{2}-\beta_{i_{n}, n}\left(1-\beta_{i_{n}, n}\right)\left\|T_{i_{n}, n} x_{n}-x_{n}\right\|^{2} \\
& =\left\|x_{n}-x^{*}\right\|^{2}+\left(2\left\|x_{n}-x^{*}\right\|^{2}+a_{i_{n}, n}\right) a_{i_{n}, n}-a(1-b)\left\|T_{i_{n}, n} x_{n}-x_{n}\right\|^{2} \\
& \leq\left\|x_{n}-x^{*}\right\|^{2}+K_{2} a_{i_{n}, n}-a(1-b)\left\|T_{i_{n}, n} x_{n}-x_{n}\right\|^{2},
\end{aligned}
$$

where

$$
K_{2}=\max _{i=1,2, \ldots, N}\left\{\sup _{n}\left\{2\left\|x_{n}-x^{*}\right\|^{2}+a_{i, n} \|\right\}\right\}<\infty .
$$

From (3.6) and (3.7), we get

$$
\begin{aligned}
{\left[1+\alpha_{n}(\tau-\gamma L)\right]\left\|x_{n+1}-x^{*}\right\|^{2} \leq } & {\left[1-\alpha_{n}(\tau-\gamma L)\left\|x_{n}-x^{*}\right\|^{2}+K_{2}\left(1-\alpha_{n} \tau\right) a_{i_{n}, n}\right.} \\
& -a(1-b)\left(1-\alpha_{n} \tau\right)\left\|T_{i_{n}, n} x_{n}-x_{n}\right\|^{2} \\
& +2 \alpha_{n}\left\langle(\gamma V-\mu F) x^{*}, x_{n+1}-x^{*}\right\rangle,
\end{aligned}
$$

which implies that

$$
\begin{aligned}
\left\|x_{n+1}-x^{*}\right\|^{2} \leq & {\left[1-\frac{2 \alpha_{n}(\tau-\gamma L)}{1+\alpha_{n}(\tau-\gamma L)}\right]\left\|x_{n}-x^{*}\right\|^{2}+\frac{K_{2}\left(1-\alpha_{n} \tau\right)}{1+\alpha_{n}(\tau-\gamma L)} a_{i_{n}, n} } \\
& -\frac{a(1-b)\left(1-\alpha_{n} \tau\right)}{1+\alpha_{n}(\tau-\gamma L)}\left\|T_{i_{n}, n} x_{n}-x_{n}\right\|^{2} \\
& +\frac{2 \alpha_{n}(\tau-\gamma L)}{1+\alpha_{n}(\tau-\gamma L)} \frac{1}{\tau-\gamma L}\left\langle(\gamma V-\mu F) x^{*}, x_{n+1}-x^{*}\right\rangle .
\end{aligned}
$$

Put

and

$$
s_{n}=\left\|x_{n}-x^{*}\right\|^{2}, b_{n}=\frac{2 \alpha_{n}(\tau-\gamma L)}{1+\alpha_{n}(\tau-\gamma L)},
$$

$$
\begin{gathered}
c_{n}=\frac{1}{2(\tau-\gamma L)}\left\langle(\gamma V-\mu F) x^{*}, x_{n+1}-x^{*}\right\rangle, \\
\sigma_{n}=\frac{a(1-b)\left(1-\alpha_{n} \tau\right)}{1+\alpha_{n}(\tau-\gamma L)}\left\|T_{i_{n}, n} x_{n}-x_{n}\right\|^{2}, \sigma_{n}^{\prime}=\frac{K_{2}}{1+\alpha_{n}(\tau-\gamma L)} a_{i_{n}, n} .
\end{gathered}
$$

Then, inequality (3.9) can be rewritten as

$$
s_{n+1} \leq\left(1-b_{n}\right) s_{n}+b_{n} c_{n}-\sigma_{n}+\sigma_{n}^{\prime} .
$$

This completes the proof.

Theorem 3.1. Suppose that the following conditions hold

i) $\lim _{n \rightarrow \infty} \alpha_{n}=0, \sum_{n=0}^{\infty} \alpha_{n}=\infty$;

ii) $\lim _{n \rightarrow \infty} a_{i, n} / \alpha_{n}=0$ for all $i=1,2, \ldots, N$.

Then, the sequence $\left\{x_{n}\right\}$ generated in Algorithm 3.1 converges strongly to $x^{\dagger} \in S$, which is the unique solution of the variational inequality $\operatorname{VI}_{S}(C, \mu F-\gamma V)$, that is,

$$
\left\langle(\mu F-\gamma V) x^{\dagger}, x^{\dagger}-y\right\rangle \leq 0, \forall y \in S \text {. }
$$


Proof. Let $x^{\dagger} \in S$ be the unique solution of variational inequality (3.10), we next show that $s_{n} \rightarrow 0$ by considering two possible cases.

Case 1. $\left\{s_{n}\right\}$ is eventually decreasing, i.e. there exists $N_{0} \geq 0$ such that $\left\{s_{n}\right\}$ is decreasing for $n \geq N_{0}$ and thus $\left\{s_{n}\right\}$ must be convergent. It then follows from (3.5) that

$$
0 \leq \sigma_{n} \leq\left(s_{n}-s_{n+1}\right)+b_{n}\left(c_{n}-s_{n}\right)+\sigma_{n}^{\prime} \rightarrow 0 .
$$

Hence $\left\|x_{n}-T_{i_{n}, n} x_{n}\right\| \rightarrow 0$ as $n \rightarrow \infty$. We further have

$$
\left\|y_{n}^{i_{n}}-x_{n}\right\|=\beta_{i_{n}, n}\left\|x_{n}-T_{i_{n}, n} x_{n}\right\| \leq b\left\|x_{n}-T_{i_{n}, n} x_{n}\right\| \rightarrow 0
$$

which implies that

$$
\left\|y_{n}^{i_{n}}-x_{n}\right\|=\left\|y_{n}-x_{n}\right\| \rightarrow 0 \text {. }
$$

It follows from the definition of $y_{n}$ that

$$
\left\|y_{n}^{i}-x_{n}\right\| \rightarrow 0
$$

for all $i=1,2, \ldots, N$. Thus, from (3.2) and the condition $\left\{\beta_{i_{n}}\right\} \subset[a, b] \subset(0,1)$, we obtain

$$
\left\|x_{n}-T_{i, n} x_{n}\right\|=\frac{1}{\beta_{i, n}}\left\|y_{n}^{i}-x_{n}\right\| \rightarrow 0
$$

for all $i=1,2, \ldots, N$.

Next, letting $B=\left\{x_{n}\right\}$, for each $i \in\{1,2, \ldots, N\}$, we have

$$
\begin{aligned}
\left\|x_{n}-T_{i} x_{n}\right\| & \leq\left\|x_{n}-T_{i, n} x_{n}\right\|+\left\|T_{i, n} x_{n}-T_{i} x_{n}\right\| \\
& \leq\left\|x_{n}-T_{i, n} x_{n}\right\|+\mathscr{D}_{B}\left(T_{i, n}, T_{i}\right) \rightarrow 0,
\end{aligned}
$$

which implies that $\lim _{n \rightarrow \infty}\left\|x_{n}-T_{i} x_{n}\right\|=0$ for all $i=1,2, \ldots, N$.

Next, we show that

$$
\limsup _{n \rightarrow \infty}\left\langle(\gamma V-\mu F) x^{\dagger}, x_{n+1}-x^{\dagger}\right\rangle \leq 0 .
$$

Since $T_{i} x=\lim _{n \rightarrow \infty} T_{i, n} x$ for all $x \in C, T_{i}$ is a nonexpansive mapping for all $i=1,2, \ldots, N$. Let $T=\frac{1}{N} \sum_{i=1}^{N} T_{i}$. It is clear that $T$ is a nonexpansive mapping and $S=\cap_{i=1}^{N} F\left(T_{i}\right)=F(T)$. Let $\left\{x_{n_{k}}\right\}$ be a subsequence of $\left\{x_{n}\right\}$ such that

$$
\limsup _{n \rightarrow \infty}\left\langle(\gamma V-\mu F) x^{\dagger}, x_{n}-x^{\dagger}\right\rangle=\lim _{k \rightarrow \infty}\left\langle(\gamma V-\mu F) x^{\dagger}, x_{n_{k}}-x^{\dagger}\right\rangle .
$$

Without loss of generality, one may assume that $x_{n_{k}} \rightarrow z \in C$. By Lemma 2.5, and

$$
\left\|x_{n}-T x_{n}\right\| \leq \frac{1}{N}\left\|x_{n}-T_{i} x_{n}\right\| \rightarrow 0
$$

as $n \rightarrow \infty$, we get that $z \in F(T)=S$. Hence, from (3.14) and Lemma $2.2 \mathrm{~b}$ ), we have

$$
\limsup _{n \rightarrow \infty}\left\langle(\gamma V-\mu F) x^{\dagger}, x_{n}-x^{\dagger}\right\rangle=\left\langle(\gamma V-\mu F) x^{\dagger}, z-x^{\dagger}\right\rangle \leq 0 .
$$

Now, from the nonexpansiveness of $P_{C}$, we have

$$
\begin{aligned}
\left\|x_{n+1}-x_{n}\right\| & =\left\|P_{C}\left[\alpha_{n} \gamma V x_{n}+\left(I-\alpha_{n} \mu F\right) y_{n}\right]-P_{C}\left(x_{n}\right)\right\| \\
& \leq\left\|\alpha_{n} \gamma V x_{n}+\left(I-\alpha_{n} \mu F\right) y_{n}-x_{n}\right\| \\
& \leq\left\|\left(I-\alpha_{n} \mu F\right) y_{n}-\left(I-\alpha_{n} \mu F\right) x_{n}\right\|+\alpha_{n}\left\|(\gamma V-\mu F) x_{n}\right\| \\
& \leq\left(1-\alpha_{n} \tau\right)\left\|y_{n}-x_{n}\right\|+K_{3} \alpha_{n},
\end{aligned}
$$


where $K_{3}=\sup _{n}\left\{\left\|(\gamma V-\mu F) x_{n}\right\|\right\}<\infty$. So, from the condition i) and (3.11), we obtain that $\left\|x_{n+1}-x_{n}\right\| \rightarrow 0$. Combining with (3.11), we get

$$
\limsup _{n \rightarrow \infty}\left\langle(\gamma V-\mu F) x^{\dagger}, x_{n+1}-x^{\dagger}\right\rangle \leq 0
$$

that is, $\limsup _{n \rightarrow \infty} c_{n} \leq 0$. From (3.5) with $x^{*}=x^{\dagger}$, we have

$$
s_{n+1} \leq\left(1-b_{n}\right) s_{n}+b_{n} c_{n}+\sigma_{n}^{\prime} .
$$

Hence, all conditions of Lemma 2.6 are satisfied. Therefore, we immediately deduce that $s_{n} \rightarrow 0$ or $x_{n} \rightarrow x^{\dagger}$.

Case 2. $\left\{s_{n}\right\}$ is not a monotone sequence. Then, from Lemma 2.7, we can define an integer sequence $\{\tau(n)\}$ for all $n \geq n_{0}$ (for some $n_{0}$ large enough) by

$$
\tau(n)=\max \left\{k \leq n: s_{k}<s_{k+1}\right\} .
$$

Moreover, $\tau$ is a nondecreasing sequence such that $\tau(n) \rightarrow \infty$ as $n \rightarrow \infty$ and $s_{\tau(n)}<s_{\tau(n+1)}$ for all $n \geq n_{0}$. From (3.5), we have

$$
0<s_{\tau(n)+1}-s_{\tau(n)} \leq b_{\tau(n)} c_{\tau(n)}+\sigma_{\tau(n)}^{\prime} .
$$

Since $b_{\tau(n)} \rightarrow 0, \sigma_{\tau(n)}^{\prime} \rightarrow 0$ and the boundedness of $\left\{c_{\tau(n)}\right\}$, we derive

$$
\lim _{n \rightarrow \infty}\left(s_{\tau(n)+1}-s_{\tau(n)}\right)=0 .
$$

By a similar argument to Case 1, we obtain

$$
\left\|x_{\tau(n)}-T_{i} x_{\tau(n)}\right\| \rightarrow 0
$$

for all $i=1,2, \ldots, N$. Also, we get

$$
s_{\tau(n)+1} \leq\left(1-b_{\tau(n)}\right) s_{n}+b_{\tau(n)} c_{\tau(n)}+\sigma_{\tau(n)}^{\prime},
$$

where $\limsup _{n \rightarrow \infty} c_{\tau(n)} \leq 0$. Since $s_{\tau(n)+1}>s_{\tau(n)}$ and $b_{\tau(n)}>0$, we have

$$
0 \leq s_{\tau(n)} \leq c_{\tau(n)}+\frac{\sigma_{\tau(n)}^{\prime}}{b_{\tau(n)}}
$$

Thus, from $\lim \sup _{n \rightarrow \infty} c_{\tau(n)} \leq 0$ and the condition iii), we get $\lim _{n \rightarrow \infty} s_{\tau(n)}=0$. Combining with (3.18), it implies that $\lim _{n \rightarrow \infty} s_{\tau(n)+1}=0$. Now, we have

$$
0 \leq s_{n} \leq \max \left\{s_{\tau(n)}, s_{n}\right\} \leq s_{\tau(n)+1} \rightarrow 0 .
$$

Therefore, $s_{n} \rightarrow 0$, that is, $\left\{x_{n}\right\}$ converges strongly to $x^{\dagger}$. This completes the proof.

Next, we have the following corollary.

Corollary 3.1. Let $C$ be a nonempty convex and closed subset of a real Hilbert space $H$. Let $F: C \rightarrow H$ be a $k$-Lipschitzian $\eta$-strongly monotone operator and $V: C \longrightarrow H$ be an $L$ Lipschitzian mapping. Let $\mathscr{T}=\left\{T_{n}\right\}$ be a sequence of nearly nonexpansive mappings from $C$ into itself with respect to the sequence $\left\{a_{n}\right\}$ such that $S=F i x(\mathscr{T}) \neq \emptyset$ and let $T$ be a mapping from $C$ into itself such that $\lim _{n \infty} \mathscr{D}_{B}\left(T_{n}, T\right)=0$ for each $B \in \mathscr{B}(C)$. Suppose that $\operatorname{Fix}(T)=$ Fix $(\mathscr{T})$, 
$0<\mu<2 \eta / k^{2}$ and $0 \leq \gamma L<\tau$, where $\tau=1-\sqrt{1-\mu\left(2 \eta-\mu k^{2}\right)}$. For an arbitrary $x_{0} \in C$, let $\left\{x_{n}\right\}$ be a sequence in $C$ generated by the following iterative method:

$$
\begin{aligned}
& y_{n}=\beta_{n} x_{n}+\left(1-\beta_{n}\right) T_{n} x_{n}, \\
& x_{n+1}=P_{C}\left[\alpha_{n} \gamma V x_{n}+\left(I-\alpha_{n} \mu F\right) y_{n}\right], n \geq 0,
\end{aligned}
$$

where $\left\{\alpha_{n}\right\} \in(0,1)$ and $\left\{\beta_{n}\right\} \in[a, b]$, with $a, b \in(0,1)$, satisfy the following conditions:

i) $\lim _{n \rightarrow \infty} \alpha_{n}=0, \sum_{n=0}^{\infty} \alpha_{n}=\infty$;

ii) $\lim _{n \rightarrow \infty} a_{n} / \alpha_{n}=0$.

Then, $\left\{x_{n}\right\}$ converges strongly to $x^{\dagger} \in S$, which is the unique solution of the variational inequality $V I_{S}(C, \mu F-\gamma V)$.

If $V x=0$ for all $x$ in Algorithm 3.1, then we have the following result for solving Problem (3.1).

Theorem 3.2. For an arbitrary $x_{0} \in C$, let $\left\{x_{n}\right\}$ be a sequence in $C$ generated by the following iterative method:

$$
\begin{aligned}
& y_{n}^{i}=\beta_{i, n} x_{n}+\left(1-\beta_{i, n}\right) T_{i, n} x_{n}, i=1,2, \ldots, N, \\
& \text { Chosse } i_{n} \text { such that }\left\|y_{n}^{i_{n}}-x_{n}\right\|=\max _{i=1,2, \ldots, N}\left\|y_{n}^{i}-x_{n}\right\|, \text { let } y_{n}=y_{n}^{i_{n}}, \\
& x_{n+1}=P_{C}\left[\left(I-\alpha_{n} \mu F\right) y_{n}\right], n \geq 0,
\end{aligned}
$$

where $\left\{\alpha_{n}\right\}$ is a sequence in $(0,1)$ and $\left\{\beta_{i, n}\right\}, i=1,2, \ldots, N$ are the sequences in $[a, b]$, with $a, b \in(0,1)$, which satisfy the following conditions:

i) $\lim _{n \rightarrow \infty} \alpha_{n}=0, \sum_{n=0}^{\infty} \alpha_{n}=\infty$;

ii) $\lim _{n \rightarrow \infty} a_{i, n} / \alpha_{n}=0$ for all $i=1,2, \ldots, N$.

Then, $\left\{x_{n}\right\}$ converges strongly to $x^{\dagger} \in S$, which is the unique solution of the variational inequality $V I_{S}(C, F)$.

\section{Applications}

4.1. Common fixed points of nonexpansive mappings. Now, we give an application of Theorem 3.1 to the problem of finding a common fixed point of a finite family of nonexpansive mappings in a real Hilbert space. We have the following theorem.

Theorem 4.1. Let $C$ be a nonempty convex closed subset of a real Hilbert space $H$. Let $F: C \rightarrow H$ be a $k$-Lipschitzian $\eta$-strongly monotone operator and $V: C \rightarrow H$ be an L-Lipschitzian mapping. Let $T_{i}, i=1,2, \ldots, N$, be nonexpansive mappings from $C$ into itself such that $S=\cap_{i=1}^{N} F i x\left(T_{i}\right) \neq \emptyset$. Suppose that $0<\mu<2 \eta / k^{2}$ and $0 \leq \gamma L<\tau$, where $\tau=1-\sqrt{1-\mu\left(2 \eta-\mu k^{2}\right)}$. For an arbitrary $x_{0} \in C$, let $\left\{x_{n}\right\}$ be a sequence in $C$ generated by the following iterative method:

$$
\begin{aligned}
& y_{n}^{i}=\beta_{i, n} x_{n}+\left(1-\beta_{i, n}\right) T_{i} x_{n}, i=1,2, \ldots, N, \\
& \text { Chosse } i_{n} \text { such that }\left\|y_{n}^{i_{n}}-x_{n}\right\|=\max _{i=1,2, \ldots, N}\left\|y_{n}^{i}-x_{n}\right\|, \text { let } y_{n}=y_{n}^{i_{n}}, \\
& x_{n+1}=P_{C}\left[\alpha_{n} \gamma V x_{n}+\left(I-\alpha_{n} \mu F\right) y_{n}\right], n \geq 0,
\end{aligned}
$$

where $\left\{\alpha_{n}\right\}$ is a sequence in $(0,1)$ and $\left\{\beta_{i, n}\right\}, i=1,2, \ldots, N$, are the sequences in $[a, b]$, with $a, b \in(0,1)$, which satisfy the following condition:

i) $\lim _{n \rightarrow \infty} \alpha_{n}=0, \sum_{n=0}^{\infty} \alpha_{n}=\infty$; 
Then, $\left\{x_{n}\right\}$ converges strongly to $x^{\dagger} \in S$, which is the unique solution of the variational inequality $V I_{S}(C, \mu F-\gamma V)$.

Proof. Applying Theorem 3.1 to $T_{i, n}=T_{i}$ for all $i=1,2, \ldots, N$ and for all $n \in \mathbb{N}$, we obtain the result this theorem immediately.

If $N=1$ in Theorem 4.1, then we have the following result.

Corollary 4.1. Let $C$ be a nonempty convex closed subset of a real Hilbert space $H$. Let $F: C \rightarrow$ $H$ be a k-Lipschitzian and $\eta$-strongly monotone operator and $V: C \rightarrow H$ be an L-Lipschitzian mapping. Let $T$ be a nonexpansive mapping from $C$ into itself such that $S=F i x(T) \neq \emptyset$. Suppose that $0<\mu<2 \eta / k^{2}$ and $0 \leq \gamma L<\tau$, where $\tau=1-\sqrt{1-\mu\left(2 \eta-\mu k^{2}\right)}$. For an arbitrary $x_{0} \in C$, let $\left\{x_{n}\right\}$ be a sequence in $C$ generated by the following iterative method:

$$
\begin{aligned}
& y_{n}=\beta_{n} x_{n}+\left(1-\beta_{n}\right) T x_{n}, \\
& x_{n+1}=P_{C}\left[\alpha_{n} \gamma V x_{n}+\left(I-\alpha_{n} \mu F\right) y_{n}\right], n \geq 0,
\end{aligned}
$$

where $\left\{\alpha_{n}\right\}$ is a sequence in $(0,1)$ and $\left\{\beta_{n}\right\} \subset[a, b]$ with $a, b \in(0,1)$, which satisfy the following condition:

i) $\lim _{n \rightarrow \infty} \alpha_{n}=0, \sum_{n=0}^{\infty} \alpha_{n}=\infty$;

Then, $\left\{x_{n}\right\}$ converges strongly to $x^{\dagger} \in S$, which is the unique solution of the variational inequality $V I_{S}(C, \mu F-\gamma V)$.

Next, we give a strong convergence theorem for finding a common fixed point of a sequence of nonexpansive mappings.

Theorem 4.2. Let $C$ be a nonempty convex closed subset of a real Hilbert space $H$. Let $F: C \rightarrow H$ be a $k$-Lipschitzian and $\eta$-strongly monotone operator and $V: C \longrightarrow H$ be an $L$ Lipschitzian mapping. Let $\left\{T_{n}\right\}$ be a sequence of nonexpansive mappings from $C$ into itself such that $S=\cap_{n=0}^{\infty} F i x\left(T_{n}\right) \neq \emptyset$. Let $T$ be a mapping from $C$ into itself such that $\lim _{n \rightarrow \infty} \mathscr{D}_{B}\left(T_{n}, T\right)=0$ for each $B \in \mathscr{B}(C)$ and Fix $(T)=\cap_{n=0}^{\infty} F i x\left(T_{n}\right)$. Let $\left\{x_{n}\right\}$ be a sequence in $C$ generated by $x_{0} \in C$ and

$$
\begin{aligned}
& y_{n}=\beta_{n} x_{n}+\left(1-\beta_{n}\right) T_{n} x_{n}, \\
& x_{n+1}=P_{C}\left[\alpha_{n} \gamma V x_{n}+\left(I-\alpha_{n} \mu F\right) y_{n}\right], \forall n \geq 0,
\end{aligned}
$$

where $0<\mu<2 \eta / k^{2}, 0 \leq \gamma L<\tau$ with $\tau=1-\sqrt{1-\mu\left(2 \eta-\mu k^{2}\right)}$ and $\left\{\alpha_{n}\right\} \subset(0,1)$ and $\left\{\beta_{n}\right\} \subset[a, b]$ with $a, b \in(0,1)$, which satisfy the following condition:

i) $\lim _{n \rightarrow \infty} \alpha_{n}=0, \sum_{n=0}^{\infty} \alpha_{n}=\infty$;

Then, the sequence $\left\{x_{n}\right\}$ converges strongly to $x^{\dagger} \in S$ which is the unique solution of the variational inequality $\operatorname{VI}_{S}(C, \mu F-\gamma V)$.

Proof. Applying Corollary 3.1 to the case $N=1$, we obtain the proof of this theorem immediately.

4.2. Common fixed points of nonexpansive semigroups. Let $C$ be a nonempty convex closed subset of a Hilbert space $H$. Motivated by Nakajo and Takahashi [11], Takahashi, Takeuchi and 
Kubota [19] gave the following definition: Let $\left\{T_{n}\right\}$ and $\mathscr{T}$ be two families of nonexpansive mappings of $C$ into itself such that

$$
\operatorname{Fix}(\mathscr{T})=\bigcap_{n=1}^{\infty} \operatorname{Fix}\left(T_{n}\right) \neq \emptyset,
$$

where $\operatorname{Fix}\left(T_{n}\right)$ is the set of all fixed points of $T_{n}$ and $\operatorname{Fix}(\mathscr{T})$ is the set of all common fixed points of $\mathscr{T}$. Then, $\left\{T_{n}\right\}$ is said to satisfy the NST-condition (I) (NST stands for Nakajo-ShimojiTakahashi) with $\mathscr{T}$ if, for each bounded sequence $\left\{z_{n}\right\} \subset C$,

$$
\lim _{n \rightarrow \infty}\left\|z_{n}-T_{n} z_{n}\right\|=0
$$

which implies that $\lim _{n \rightarrow \infty}\left\|z_{n}-T z_{n}\right\|=0$ for all $T \in \mathscr{T}$.

A family $\mathscr{T}=\{T(s): 0 \leq s<\infty\}$ of mappings of $C$ into itself is called a one-parameter nonexpansive semigroup on $C$ if it satisfies the following conditions (see [14]):

i) $T(0) x=x$ for all $x \in C$;

ii) $T(s+t)=T(s) T(t)$ for all $s, t \geq 0$;

iii) $\|T(s) x-T(s) y\| \leq\|x-y\|$ for all $s \geq 0$ and $x, y \in C$;

iv) for any $x \in C, s \mapsto T(s) x$ is continuous.

We need the following lemma.

Lemma 4.1. [12] Let $C$ be a nonempty closed convex subset of a Hilbert space $H$ and let $\mathscr{T}=\{T(s): 0 \leq s<\infty\}$ be a one-parameter nonexpansive semigroup on $C$ with Fix $(\mathscr{T}) \neq \emptyset$. Let $\left\{t_{n}\right\}$ be a sequence of real numbers with $0<t_{n}<\infty$ such that $\lim _{n \rightarrow \infty} t_{n}=\infty$. For $n \in \mathbb{N}$, define a mapping $T_{n}$ of $C$ into itself by

$$
T_{n} x=\frac{1}{t_{n}} \int_{0}^{t_{n}} T(s) x d s, \text { for all } x \in C .
$$

Then, $\left\{T_{n}\right\}$ satisfies the NST-condition (I) with $\mathscr{T}=\{T(s): 0 \leq s<\infty\}$.

Theorem 4.3. Let $C$ be a nonempty convex closed subset of a real Hilbert space $H$. Let $\mathscr{T}_{i}=\left\{T_{i}(s): 0 \leq s<\infty\right\}, i=1,2, \ldots, N$, be one-parameter nonexpansive semigroups on $C$ with $S=\cap_{i=1}^{N} F i x\left(\mathscr{T}_{i}\right) \neq \emptyset$. Let $F: C \rightarrow H$ be a $k$-Lipschitzian and $\eta$-strongly monotone operator and $V: C \rightarrow H$ be an L-Lipschitzian mapping. For an arbitrary $x_{0} \in C, 0<\mu<2 \eta / k^{2}$ and $0 \leq \gamma L<\tau$ with $\tau=1-\sqrt{1-\mu\left(2 \eta-\mu k^{2}\right)}$, let $\left\{x_{n}\right\}$ be a sequence in $C$ defined by

$$
\begin{aligned}
& y_{n}^{i}=\beta_{i, n} x_{n}+\left(1-\beta_{i, n}\right) T_{i, n} x_{n}, i=1,2, \ldots, N, \\
& \text { Chosse } i_{n} \text { such that }\left\|y_{n}^{i_{n}}-x_{n}\right\|=\max _{i=1,2, \ldots, N}\left\|y_{n}^{i}-x_{n}\right\|, \text { let } y_{n}=y_{n}^{i_{n}}, \\
& x_{n+1}=P_{C}\left[\alpha_{n} \gamma V x_{n}+\left(I-\alpha_{n} \mu F\right) y_{n}\right], n \geq 0,
\end{aligned}
$$

with $T_{i, n} x=\frac{1}{t_{n}} \int_{0}^{t_{n}} T_{i}(s) x d s$, for all $i=1,2, \ldots, N$ and $x \in C$, where $\left\{\alpha_{n}\right\}$ is a sequence in $(0,1)$, $\left\{\beta_{i, n}\right\}, i=1,2, \ldots, N$ are the sequences in $[a, b]$, with $a, b \in(0,1)$, and $\left\{t_{n}\right\}$ is a sequence in $(0, \infty)$, which satisfy the following conditions:

i) $\lim _{n \rightarrow \infty} \alpha_{n}=0, \sum_{n=0}^{\infty} \alpha_{n}=\infty$;

ii) $\lim _{n \rightarrow \infty} t_{n}=\infty$ and $\sum_{n=0}^{\infty} \frac{\left|t_{n+1}-t_{n}\right|}{t_{n+1}}<\infty$. 
Then, $\left\{x_{n}\right\}$ converges strongly to $x^{\dagger} \in S$, which is the unique solution of the variational inequality $V I_{S}(C, \mu F-\gamma V)$.

Proof. We will apply the proof of Theorem 3.1. First, for any $B \in \mathscr{B}(C)$, since $T_{i, n}(s)$ is nonexpansive for all $s \geq 0$ and for all $i=1,2, \ldots, N$, we have that

$$
K=\max _{i=1,2, \ldots, N}\left\{\sup _{s \geq 0, n \geq 1, x \in B}\left\{\left\|T_{i, n}(s) x\right\|\right\}\right\}<\infty .
$$

Thus, for each $i=1,2, \ldots, N$, we have

$$
\begin{aligned}
\left\|T_{i, n} x-T_{i, n+1} x\right\| & =\left\|\frac{1}{t_{n}} \int_{0}^{t_{n}} T_{i, n}(s) x d s-\frac{1}{t_{n+1}} \int_{0}^{t_{n+1}} T_{i, n+1}(s) x d s\right\| \\
& \leq \frac{\left|t_{n+1}-t_{n}\right|}{t_{n} t_{n+1}}\left\|\int_{0}^{t_{n}} T_{i, n}(s) x d s\right\|+\frac{1}{t_{n+1}} \int_{t_{n}}^{t_{n+1}} T_{i, n+1}(s) x d s \| \\
& \leq 2 K \frac{\left|t_{n+1}-t_{n}\right|}{t_{n+1}}
\end{aligned}
$$

So, if $\left\{t_{n}\right\}$ satisfies the condition $\sum_{n=0}^{\infty} \frac{\left|t_{n+1}-t_{n}\right|}{t_{n+1}}<\infty$, then we obtain that $\sum_{n=0}^{\infty} \mathscr{D}_{B}\left(T_{n}, T_{n+1}\right)<$ $\infty$ for each $B \in \mathscr{B}(C)$. Thus, it follows from Remark 1.1 that $\lim _{n \rightarrow \infty} \mathscr{D}_{B}\left(T_{n}, T\right)=0$ for each $B \in \mathscr{B}(C)$.

Now, by an argument similar to the proof of Theorem 3.1, we get that

$$
\lim _{n \rightarrow \infty}\left\|x_{n}-T_{i, n} x_{n}\right\|=0
$$

for all $i=1,2, \ldots, N$. So, by use of Lemma 4.1, we have

$$
\lim _{n \rightarrow \infty}\left\|x_{n}-T_{i}(s) x_{n}\right\|=0,
$$

for all $i=1,2, \ldots, N$ and $s \geq 0$. Let $\left\{x_{n_{k}}\right\}$ be a subsequence of $\left\{x_{n}\right\}$ such that

$$
\limsup _{n \rightarrow \infty}\left\langle(\gamma V-\mu F) x^{\dagger}, x_{n}-x^{\dagger}\right\rangle=\lim _{k \rightarrow \infty}\left\langle(\gamma V-\mu F) x^{\dagger}, x_{n_{k}}-x^{\dagger}\right\rangle
$$

where $x^{\dagger}$ is a unique solution of the variational inequality $\mathrm{VI}_{S}(C, \mu F-\gamma V)$. Without loss of generality, one may assumes that $x_{n_{k}} \rightarrow z \in C$. By Lemma 2.5 and (4.5), one obtains that $z \in \operatorname{Fix}\left(T_{i}(s)\right)$ for all $s \geq 0$ and $i=1,2, \ldots, N$. Thus, $z \in S$. Hence, from (4.6), we have

$$
\limsup _{n \rightarrow \infty}\left\langle(\gamma V-\mu F) x^{\dagger}, x_{n}-x^{\dagger}\right\rangle=\left\langle(\gamma V-\mu F) x^{\dagger}, z-x^{\dagger}\right\rangle \leq 0 .
$$

The rest of the proof follows the pattern of Theorem 3.1.

Remark 4.1. The sequences $\alpha_{n}=\frac{1}{n}, t_{n}=\sqrt{n}$, and $\beta_{i, n}=\frac{1}{2}$ satisfy all the conditions i)-ii) in Theorem 4.3.

We also have the following result.

Corollary 4.2. Let $C$ be a nonempty convex closed subset of a real Hilbert space $H$. Let $\mathscr{T}=\{T(s): 0 \leq s<\infty\}$ be one-parameter nonexpansive semigroup on $C$ with $S=F i x(\mathscr{T}) \neq \emptyset$. Let $F: C \rightarrow H$ be a $k$-Lipschitzian and $\eta$-strongly monotone operator and $V: C \rightarrow H$ be 
an L-Lipschitzian mapping. For an arbitrary $x_{0} \in C, 0<\mu<2 \eta / k^{2}$ and $0 \leq \gamma L<\tau$ with $\tau=1-\sqrt{1-\mu\left(2 \eta-\mu k^{2}\right)}$, let $\left\{x_{n}\right\}$ be a sequence in $C$ defined by

$$
\begin{aligned}
& y_{n}=\beta_{n} x_{n}+\left(1-\beta_{n}\right) T_{n} x_{n}, \\
& x_{n+1}=P_{C}\left[\alpha_{n} \gamma V x_{n}+\left(I-\alpha_{n} \mu F\right) y_{n}\right], n \geq 0,
\end{aligned}
$$

with $T_{n} x=\frac{1}{t_{n}} \int_{0}^{t_{n}} T(s) x d s$, for all $x \in C$, where $\left\{\alpha_{n}\right\}$ is a sequence in $(0,1),\left\{\beta_{n}\right\}$ is the sequence in $[a, b]$, with $a, b \in(0,1)$, and $\left\{t_{n}\right\}$ is a sequence in $(0, \infty)$, which satisfy the following conditions:

i) $\lim _{n \rightarrow \infty} \alpha_{n}=0, \sum_{n=0}^{\infty} \alpha_{n}=\infty$;

ii) $\lim _{n \rightarrow \infty} t_{n}=\infty$ and $\sum_{n=0}^{\infty} \frac{\left|t_{n+1}-t_{n}\right|}{t_{n+1}}<\infty$.

Then, $\left\{x_{n}\right\}$ converges strongly to $x^{\dagger} \in S$, which is the unique solution of the variational inequality $V I_{S}(C, \mu F-\gamma V)$.

4.3. Common null points of monotone operators. Let $C$ be a nonempty convex closed subset of a real Hilbert space $H$. Let $F: C \rightarrow H$ be a $k$-Lipschitzian and $\eta$-strongly monotone operator and $V: C \rightarrow H$ be an $L$-Lipschitzian mapping. Let $A_{i}: D\left(A_{i}\right) \subset C \longrightarrow 2^{H}, i=1,2, \ldots, N$ be monotone operators such that $S=\cap_{i=1}^{N} A_{i}^{-1}(0) \neq \emptyset$ and $\overline{D\left(A_{i}\right)} \subset C \subset \cap_{r>0} R\left(I+r A_{i}\right)$ for all $i=1,2, \ldots, N$.

Now, to find an element $x^{*} \in S$, we introduce the following iterative method:

$$
\begin{aligned}
& y_{n}^{0}=x_{n}, \\
& y_{n}^{i}=\beta_{i, n} x_{n}+\left(1-\beta_{i, n}\right) J_{i, n} x_{n}, J_{i, n}=\left(I+r_{i, n} A_{i}\right)^{-1}, i=1,2, \ldots, N, \\
& \text { Chosse } i_{n} \text { such that }\left\|y_{n}^{i_{n}}-x_{n}\right\|=\max _{i=1,2, \ldots, N}\left\|y_{n}^{i}-x_{n}\right\|, \text { let } y_{n}=y_{n}^{i_{n}}, \\
& x_{n+1}=P_{C}\left[\alpha_{n} \gamma V x_{n}+\left(I-\alpha_{n} \mu F\right) y_{n}^{N}\right], n \geq 0,
\end{aligned}
$$

where $\left\{\alpha_{n}\right\}$ is a sequence in $(0,1)$ and $\left\{\beta_{i, n}\right\}, i=1,2, \ldots, N$ are the sequences in $[a, b]$, with $a, b \in(0,1)$, and $\left\{r_{i, n}\right\}$ are the sequences of positive numbers for all $i=1,2, \ldots, N$.

Theorem 4.4. If the sequences $\left\{r_{i, n}\right\},\left\{\beta_{i, n}\right\}, i=1,2, \ldots, N$, and $\left\{\alpha_{n}\right\}$ satisfy the following conditions:

i) $\lim _{n \rightarrow \infty} \alpha_{n}=0, \sum_{n=0}^{\infty} \alpha_{n}=\infty$;

ii) $\min _{i=1,2, \ldots, N}\left\{\inf _{n}\left\{r_{i, n}\right\}\right\} \geq r>0, \sum_{n=1}^{\infty}\left|r_{i, n+1}-r_{i, n}\right|<\infty$ for all $i=1,2, \ldots, N$,

then the sequence $\left\{x_{n}\right\}$ defined by (4.9) converges strongly to $x^{\dagger} \in S$, which is the unique solution of variational inequality $V I_{S}(C, \mu F-\gamma V)$.

Proof. Let $T_{i, n}=J_{i, n}$ for all $i=1,2, \ldots, N$ and $n \in \mathbb{N}$. Then, $\mathscr{T}_{i}=\left\{T_{i, n}\right\}$ are sequences of nonexpansive mappings for all $i=1,2, \ldots, N$ and $S=\cap_{i=1}^{N} F i x\left(\mathscr{T}_{i}\right) \neq \emptyset$.

First, we show that $\sum_{n=0}^{\infty} \mathscr{D}_{B}\left(T_{i, n+1}, T_{i, n}\right)<\infty$ for all $i=1,2, \ldots, N$ and for all $B \in \mathscr{B}(C)$. Let $B \in \mathscr{B}(C)$, and set $K=\max _{i=1,2, \ldots, N}\left\{\sup _{n}\left\{\left\|z-J_{i, n+1} z\right\|: z \in B\right\}\right\}<\infty$. From Lemma 2.6, for 
each $i \in\{1,2, \ldots, N\}$, we have

$$
\begin{aligned}
\mathscr{D}_{B}\left(T_{i, n+1}, T_{i, n}\right) & =\sup \left\{\left\|J_{i, n+1} z-J_{i, n} z\right\|: z \in B\right\} \\
& \leq \sup \left\{\frac{\left|r_{i, n+1}-r_{i, n}\right|}{r_{i, n+1}}\left\|z-J_{i, n+1} z\right\|: z \in B\right\} \\
& \leq K \frac{\left|r_{i, n+1}-r_{i, n}\right|}{r} .
\end{aligned}
$$

Hence, $\sum_{n=0}^{\infty} \mathscr{D}_{B}\left(T_{i, n+1}, T_{i, n}\right)<\infty$ for all $i=1,2, \ldots, N$. Since $\sum_{n=1}^{\infty}\left|r_{i, n+1}-r_{i, n}\right|<\infty$, we have that $\left\{r_{i, n}\right\}$ are Cauchy sequences for all $i=1,2, \ldots, N$. Suppose $\lim _{n \rightarrow \infty} r_{i, n}=r_{i} \geq r$ for all $i=1,2, \ldots, N$. Setting $T_{i}=J_{r_{i}}^{A_{i}}$ for all $i=1,2, \ldots, N$, we have

$$
\left\|T_{i, n} x-T_{i} x\right\|=\left\|J_{i, n} x-J_{r_{i}}^{A_{i}} x\right\| \leq \frac{\left|r_{i, n}-r_{i}\right|}{r_{i}}\left\|x-T_{i} x\right\|, \forall x \in C,
$$

which implies that $T_{i} x=\lim _{n \rightarrow \infty} T_{i, n} x$ for all $x \in C$. So, by use of Theorem 3.1, we have that $\left\{x_{n}\right\}$ converges strongly to $x^{\dagger} \in S$, which is the unique solution of variational inequality $\mathrm{VI}_{S}(C, \mu F-\gamma V)$.

Corollary 4.3. Let $C$ be a nonempty convex closed subset of a Hilbert space $H$. Let $F$ : CrightarrowH be a $k$-Lipschitzian and $\eta$-strongly monotone operator and $V:$ CrightarrowH be an L-Lipschitzian mapping. Let $A: D(A) \subset C \longrightarrow 2^{H}$ be a monotone operator such that $S=A^{-1}(0) \neq \emptyset$ and $\overline{D(A)} \subset C \subset \cap_{r>0} R(I+r A)$. If the sequences $\left\{r_{n}\right\}$ and $\left\{\alpha_{n}\right\}$ satisfy the following conditions:

i) $\lim _{n \rightarrow \infty} \alpha_{n}=0, \sum_{n=0}^{\infty} \alpha_{n}=\infty$;

ii) $\inf _{n}\left\{r_{n}\right\} \geq r>0, \sum_{n=1}^{\infty}\left|r_{n+1}-r_{n}\right|<\infty$,

then the sequence $\left\{x_{n}\right\}$ defined by $x_{0} \in C$ and

$$
x_{n+1}=P_{C}\left[\alpha_{n} \gamma V x_{n}+\left(I-\alpha_{n} \mu F\right) J_{r_{n}}^{A} x_{n}\right]
$$

converges strongly to $x^{\dagger} \in S$, which is the unique solution of the variational inequality $\operatorname{VI}_{S}(C, \mu F-$ $\gamma V)$.

\section{NUMERICAL EXPERIMENTS}

In this section, we will verify the proposed algorithm in Theorem 3.2. The algorithms are implemented in MATLAB 7.0 running on a HP Compaq 510, Core(TM) 2 Duo CPU. T5870 with $2.0 \mathrm{GHz}$ and 2GB RAM.

Example 5.1. Consider the problem of finding an element $x^{\dagger} \in S$ such that

$$
\varphi\left(x^{\dagger}\right)=\min _{x \in S} \varphi(x)
$$

where

$$
\begin{aligned}
& \varphi(x)=\left(x_{1}+1\right)^{2}+\left(x_{2}-1\right)^{2}+x_{3}^{2} \text { for all } x=\left(x_{1}, x_{2}, x_{3}\right) \in \mathbb{R}^{3}, \\
& S=\cap_{i=1}^{100} C_{i} \neq \emptyset, \\
& C_{i}=\left\{\left(x_{1}, x_{2}, x_{3}\right):\left(x_{1}-1 / i\right)^{2}+x_{2}^{2}+\left(x_{3}+1 / i\right)^{2} \leq 2\right\}, i=1,2, \ldots, 100 .
\end{aligned}
$$


It is easy to show that $\varphi$ is a convex function, $F=\nabla \varphi$ is a 2-Lipschitz and 2-strongly monotone operator, and $x^{\dagger}=(-1,1,0)$ is the minimum point of $\varphi$ on $S$.

Let $T_{i}=P_{C_{i}}, i=1,2, \ldots, 100$, where $P_{C_{i}}$ is metric projections from $\mathbb{R}^{3}$ onto $C_{i}$. Suppose that $P_{C_{i}}$ is given by the perturbation operator $P_{C_{i}}^{n}$, defined by

$$
P_{C_{i}}^{n} x= \begin{cases}P_{C_{i}} x, & \text { if } x \in C_{i}, \\ P_{C_{i}} x+a_{i, n} e, & \text { if } x \notin C_{i},\end{cases}
$$

where $\left\{a_{i, n}\right\}$ is a sequence of positive numbers such that $\lim _{n \rightarrow \infty} a_{i, n}=0, \sum_{n=0}^{\infty}\left|a_{i, n}-a_{i, n+1}\right|<\infty$ and $e \in \mathbb{R}^{3}$ such that $\|e\| \leq 1$ for all $i=1,2, \ldots, 100$.

Let $T_{i, n}=P_{C_{i}}^{n}$ for all $i=1,2, \ldots, N$. Then $\mathscr{T}_{i}=\left\{T_{i, n}\right\}$ is a sequence of nearly nonexpansive mappings with respect to the sequence $\left\{a_{i, n}\right\}$. Indeed, for all $x, y \in \mathbb{R}^{3}$, we consider the following cases

Case 1. If $x, y \in C_{i}$ or $x, y \in \mathbb{R}^{3} \backslash C_{i}$, then

$$
\left\|T_{i, n} x-T_{i, n} y\right\|=\left\|P_{C_{i}} x-P_{C_{i}} y\right\| \leq\|x-y\| .
$$

Case 2. If $x \in C_{i}$ and $y \in \mathbb{R}^{3} \backslash C_{i}$, then

$$
\left\|T_{i, n} x-T_{i, n} y\right\|=\left\|P_{C_{i}} x-P_{C_{i}} y-a_{i, n} e\right\| \leq\|x-y\|+a_{i, n} .
$$

From (5.3) and (5.4), we deduce that $\left\{\mathscr{T}_{i}\right\}$ is the sequence of nearly nonexpansive mappings with respect to the sequence $\left\{a_{i, n}\right\}$, for all $i=1,2, \ldots, 100$.

It is easy to see that

$$
S=\cap_{i=1}^{100} F\left(\mathscr{T}_{i}\right)=\cap_{i=1}^{100} C_{i} \neq \emptyset .
$$

Now, for each $x \in \mathbb{R}^{3}$, we have $\left\|T_{i, n} x-T_{i} x\right\| \leq a_{i, n} \rightarrow 0$, as $n \rightarrow \infty$, which implies that $\lim _{n \rightarrow \infty} \mathscr{T}_{i, n} x=T_{i} x$, for all $i=1,2, \ldots, 100$.

We know that problem (5.1) is equivalent to the following variational inequality problem.

Find an element $x^{\dagger} \in S$ such that

$$
\left\langle F x^{\dagger}, x^{\dagger}-y\right\rangle \leq 0, \forall y \in S
$$

Suppose $a_{i, n}=1 / n$ and $e=(1,0,0)$ for all $i=1,2, \ldots, 100$. Applying the iterative methods (1.2) and (3.14) to $\mu=9 / 10, \beta_{i, n}=1 / 2$ for all $i=1,2, \ldots, 100$, and $x^{0}=(1,2,3)$, we obtain the following table of results.

Stop condition: TOL $_{n}=\left\|x_{n}-x^{\dagger}\right\|<$ err

\begin{tabular}{llllllll}
\hline \multicolumn{2}{l}{ Algorithm (3.21) with $\alpha_{n}=n^{-0.25}$} & & \multicolumn{2}{l}{ Algorithm (1.2) with } & \multicolumn{2}{l}{$\alpha_{n}=1 / n$} \\
\hline err & TOL $_{n}$ & $n$ & & err & TOL $_{n}$ & $n$ \\
\cline { 1 - 3 } \cline { 5 - 8 } $10^{-7}$ & $1.407897 \mathrm{e}-008$ & 10 & & $10^{-7}$ & $9.994859 \mathrm{e}-008$ & 1784 \\
$10^{-8}$ & $1.635852 \mathrm{e}-010$ & 11 & & $10^{-8}$ & $9.998582 \mathrm{e}-009$ & 6409 \\
$10^{-9}$ & $1.635852 \mathrm{e}-010$ & 11 & & $10^{-9}$ & $9.999927 \mathrm{e}-010$ & 23030 \\
$10^{-10}$ & $5.379840 \mathrm{e}-012$ & 12 & & $10^{-10}$ & $9.999882 \mathrm{e}-011$ & 82779 \\
\hline
\end{tabular}

TABLE 1. Table of numerical results for Algorithm (3.21) and Algorithm (1.2). 
Now, we applying our algorithm (Algorithm (3.21)) with the sequence $\left\{\alpha_{n}\right\}$ defined by

$$
\alpha_{n}= \begin{cases}n^{-0.25}, & \text { if } n \text { odd }, \\ n^{-0.2}, & \text { if } n \text { even }\end{cases}
$$

We obtain the following table of numerical results.

\begin{tabular}{lll}
\multicolumn{3}{l}{ Stop condition: $\mathrm{TOL}_{n}=\left\|x_{n}-x^{\dagger}\right\|<\mathrm{err}$} \\
\hline err & TOL $_{n}$ & $n$ \\
\hline $10^{-7}$ & $1.635852 \mathrm{e}-009$ & 11 \\
$10^{-8}$ & $1.635852 \mathrm{e}-009$ & 11 \\
$10^{-9}$ & $9.357268 \mathrm{e}-010$ & 12 \\
$10^{-10}$ & $5.379840 \mathrm{e}-011$ & 13 \\
\hline
\end{tabular}

TABLE 2. Table of numerical results for Algorithm (3.21) with $\left\{\alpha_{n}\right\}$ defined by (5.6).

The behaviours of the functions $\mathrm{TOL}_{n}$ for our algorithm and Algorithm (1.2) in the above cases after 100 iteration steps are presented in Figure 1.

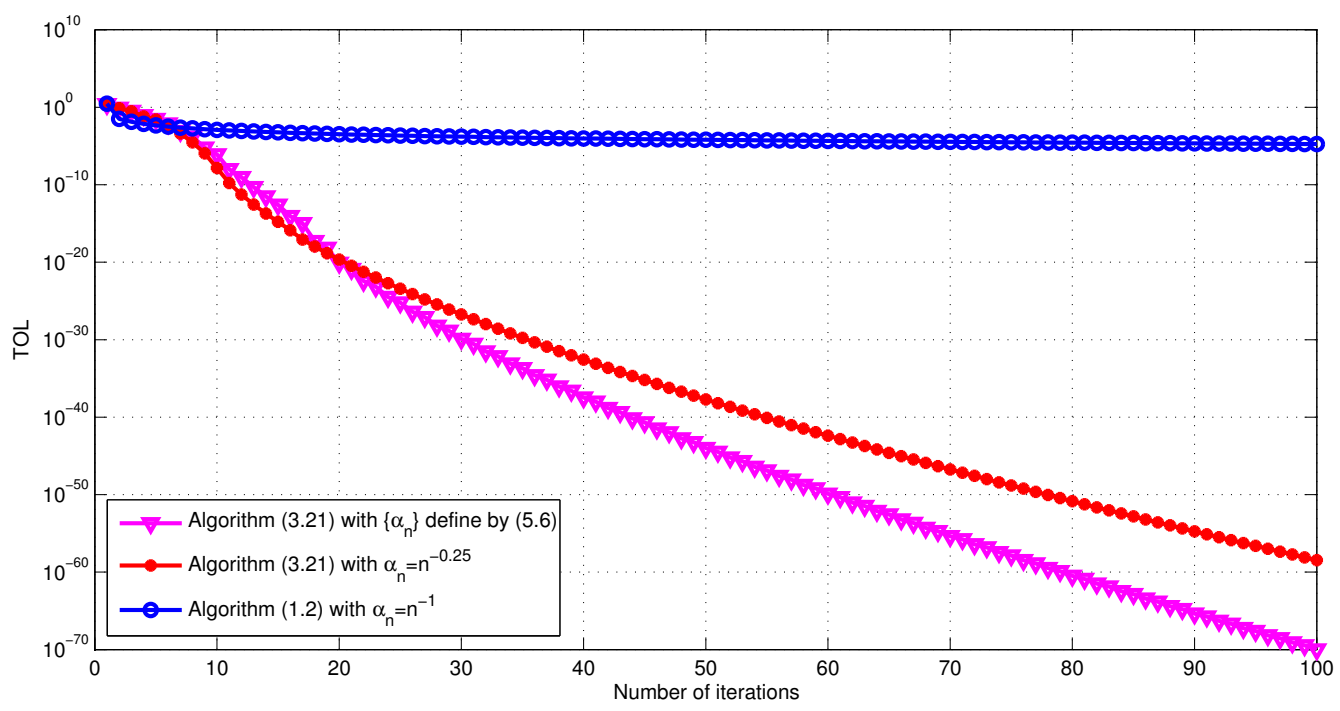

FIGURE 1. The behaviour of the function $\mathrm{TOL}_{n}$.

\section{Remark 5.1.}

i) In this section, we use the symbol $\mathrm{TOL}_{n}$ to denote the error between the approximate solution $x^{n}$ and the exact solution $x^{\dagger}$, that is, $\mathrm{TOL}_{n}=\left\|x^{n}-x^{\dagger}\right\|$.

ii) In this example (for our algorithm), the sequence $\left\{\alpha_{n}\right\}$ defined by $\alpha_{n}=n^{-0.25}$ satisfies the condition i) of Theorem 3.2 but do not satisfy the condition $\sum_{n=1}^{\infty}\left|\alpha_{n+1}-\alpha_{n}\right|<\infty$, and the sequence $\left\{\alpha_{n}\right\}$ defined by (5.6) satisfies the conditions i) of Theorem 3.2 but do not satisfy the conditions i) and ii) in Theorem 1.1. 
A PARALLEL ITERATIVE METHOD

\section{Acknowledgements}

The third author was supported by the Science and Technology Fund of Thai Nguyen University of Technology (TNUT), Vietnam.

\section{REFERENCES}

[1] K. Aoyama, Y. Kimura, W. Takahashi, M. Toyoda, Approximation of common fixed points of a countable family of nonexpansive mappings in a Banach space, Nonlinear Anal. 67 (2007), 2350-2360.

[2] L.C. Ceng, Q.H. Ansari, J.C. Yao, Some iterative methods for finding fixed points and for solving constrained convex minimization problems, Nonlinear Anal. 74 (2011), 5286-5302.

[3] S.Y. Cho, X. Qin, On the strong convergence of an iterative process for asymptotically strict pseudocontractions and equilibrium problems, Appl. Math. Comput. 235 (2014), 430-438.

[4] P. L. Combettes, On the numerical robustness of the parallel projection method in signal synthesis, IEEE Signal Process. Lett. 8 (2001), 45-47.

[5] P. Duan, X. Zheng, Bounded pertrbation resilience of a viscosity iterative method for split feasibility problems, J. Nonlinear Funct. Anal. 2019 (2019), Article ID 1.

[6] K. Goebel, W.A. Kirk, Topics in Metric Fixed Point Theory, Cambridge Stud. Adv. Math., vol. 28, Cambridge Univ. Press, Cambridge, UK 1990.

[7] K. Goebel and S. Reich, Uniform Convexity, Hyperbolic Geometry, and Nonexpansive Mappings, Marcel Dekker, New York, 1984.

[8] T. H. Kim and H. K. Xu, Robustness of Mann's algorithm for nonexpansive mappings, J. Math. Anal. Appl. 327 (2007), 1105-1115.

[9] P.E. Maingé, Strong convergence of projected subgradient methods for nonsmooth and nonstrictly convex minimization, Set-Valued Anal. (2008), 899-912.

[10] A. Moudafi, Vicosity approximation methods for fixed point problems, J. Math. Anal. Appl. 241 (2000), 45-55.

[11] K. Nakajo, W. Takahashi, Strong convergence theorem for nonexpansive mappings and nonexpansive semigroup, J. Math. Anal. Appl. 279 (2003), 372-379.

[12] K. Nakajo, K. Shimoji, W. Takahashi, Strong convergence to common fixed points of families of nonexpansive mappings in Banach spaces, J. Nonlinear Convex Anal. 8 (2007), 11-34.

[13] X. Qin, L. Wang, J.C. Yao, Inertial splitting method for maximal monotone mappings, J. Nonlinear Convex Anal. 21 (2020), 2325-2333.

[14] S. Reich, Product formulas, nonlinear semigroups, and accretive operators, J. Funct. Anal. 36 (1980), 147-168.

[15] S. Reich, Extension problems for accretive sets in Banach spaces, J. Funct. Anal. 26 (1977), 378-395.

[16] D. R. Sahu, S.M. Kang, V. Sagar, Approximation of common fixed points of a sequence of nearly nonexpansive mappings and solutions of variational inequality problems, J. Appl. Math. 2012 (2012), Article ID 902437.

[17] G. Stampacchia, Formes bilineaires coercitives sur les ensembles convexes, C. R. Acad. Sci. Paris 258 (1964), 4413-4416.

[18] W. Takahashi, Nonlinear Functional Analysis, Fixed Point Theory and Its Applications, Yokohama Publishers, Yokohama, 2000.

[19] W. Takahashi, Y. Takeuchi, R. Kubota, Strong convergence theorems by hybrid methods for families of nonexpansive mappings in Hilbert spaces, J. Math. Anal. Appl. 341 (2008), 276-286.

[20] T.M. Tuyen, N.S. Ha, Parallel iterative method for a finite family of sequences of nearly nonexpansive mappings in Hilbert spaces, Comput. Appl. Math. 37 (2018), 3093-3117.

[21] T.M. Tuyen, A cyclic iterative method for solving a class of variational inequalities in Hilbert spaces, Optimization, 67 (2018), 1769-1796.

[22] T.M. Tuyen, Strong convergence theorems for a finite family of sequences of nearly nonexpansive mappings in Hilbert spaces, Numer. Funct. Anal. Optim. 39 (2018), 1034-1053.

[23] N.C. Wong, D.R. Sahu, J.C. Yao, A generalized hybrid steepest-descent method for variational inequalities in Banach spaces, Fixed Point Theory Appl. 2011 (2011), Article ID 754702.

[24] Z. Xue, H. Zhou, Y.J. Cho, Iterative solutions of nonlinear equations for m-accretive operators in Banach spaces, J. Nonlinear Convex Anal. 1 (2000), 313-320. 
[25] Y. Yamada, The hybrid steepest-descent method for variational inequalities problems over the intersection of the fixed point sets of nonexpansive mappings, In: Butnariu, D., Censor, Y., Reich, S. (eds.) Inhently Parallel Algorithms in Feasibility and Optimization and Their Applications, pp. 473-504, North-Holland, Amsterdam, 2001. 